\title{
The cultural halo effect: Black and white women rate black and white men
}

\author{
M. J. INTONS-PETERSON and ARLENE K. SAMUELS \\ Indiana University, Bloomington, Indiana 47401
}

\begin{abstract}
In an exploratory study, black and white college women rated black and white men on traits associated with masculinity, femininity, and social desirability using the Bem scale. Black women rated black men as more masculine than white men, whereas white women characterized both black and white men as less masculine than the ratings assigned by black women to black men but as more masculine than the ratings assigned by black women to white men. Both black and white women attributed feminine socially desirable traits to black and white men in approximately equal proportions. These data were consistent with a "cultural halo" hypothesis.
\end{abstract}

As the study of the development of sex-role differences has intensified and become more sophisticated, an increasing emphasis has been placed on the extent to which sex-role expectations and influences are found in various ethnic groups within the United States. It may be assumed that the development of identity and self-image emerges gradually from an interaction of environmental conditions, attitudes, beliefs, and expectations about many roles, of which sex and ethnic identity are two of the most powerful. The present study was designed to explore some aspects of sex and ethnic attributions by assessing the traits black and white women assign to males of the two ethnic groups.

The attributions of differential characteristics to the two sex roles have been extensively researched, with reasonably systematic results. Both women and men attribute to women such traits usually considered socially desirable as poise, sensitivity, modesty, and warmth (e.g., McKee \& Sherriffs, 1959; Peterson, 1975; Rosenkrantz, Vogel, Bee, Broverman, \& Broverman, 1968). These traits, labeled as a warmth-expressiveness cluster by Broverman, Vogel, Broverman, Clarkson, and Rosenkrantz (1972), describe some of the parameters of the stereotypic female sex role in American society. In addition, research has indicated that certain other characteristics, typically identified as socially desirable, are attributed to men by both sexes. Men tend to be described as aggressive, competent, independent, and dominant, a collection of traits Broverman et al. (1972) called the competency cluster. Thus, although there are some indications that the sex-role stereotype for men is expanding to include some socially desirable traits usually attributed to women (O'Leary \& Depner, 1975; Peterson, 1975),

Requests for reprints should be sent to M. J. Intons-Peterson, Department of Psychology, Indiana University, Bloomington, Indiana 47401. The authors wish to thank Frances Cherry for a critical reading of the manuscript. the cited research has continued to demonstrate evidence of the two sex-typed clusters of traits.

Most of the experimental work providing substantiation for these sex-role attributions used white students as the subjects and may not be generalizable to other American ethnic groups. Indeed, articles in the popular press and in the research literature have questioned the accuracy of such sex-role attributions when applied to black Americans. For example, a number of writers (Lerner, 1973; Moynihan, 1965; Pettigrew, 1964; Poussaint, 1971) have maintained that the sex-role patterns and expectations have been almost diametrically opposed for blacks. Epstein (1973), Murray and Mednick (1975), and Weston and Mednick (1970) found that black women characterized themselves or indicated attitudes that were more similar to those typically associated with white males than with white females. The black women had higher achievements and provided less fear-of-success imagery than white women. These ideas may be called the "opposite culture" view.

There are some problems with the opposite culture view: (1) The relevant evidence for black males is scanty; and (2) Gump's (1975) work casts doubt on the hypothesis of reversed sex-role stereotypes among blacks. She found that black female college students were more likely to define themselves in terms of roles such as those associated with the home than were white female students.

La Rue (1976) argued persuasively that some members of the black movement have espoused the "American values of male superiority and female inferiority" and that the black women are being encouraged to subscribe to the belief that black male freedom is primary in importance. This position, the "cultural halo" perspective, would predict that black college women, a group with high achievement potential, might attribute particularly great strength to black males. Simultaneously, another aspect of the black 
liberation (and other liberation) movements is the development of pride in the group with which one is affiliated. The manifestation of this pride by black women should be demonstrated by the assignment of greater masculine characteristics to black men than to white men.

Thus, the two positions described above yield differing predictions about the likely attributions of traits by black and white women to men of the two groups. The opposite culture view predicts that black women should attribute fewer masculine and more feminine traits to black men than to white men. White women should show a similar but less exaggerated trend. The cultural halo position predicts that black women should rate black men as more masculine than white men, compared to the ratings white women assign to men of the two groups. Black women would be expected to rate black men as less feminine than white men and, while the obvious prediction is that white women should perceive white men as less feminine than black men, the experimental evidence cited earlier signals a growing tendency to attribute socially desirable feminine traits to men. Hence, it seems likely that no differences should emerge on the femininity ratings.

These predictions were assessed in an exploratory study on scales designed to measure feminine, masculine, and androgynous characteristics. The scales designated as "feminine" corresponded closely to the socially desirable traits that Broverman et al. (1972) associated with women; the scales designated as "masculine" generally corresponded to the traits associated with men. In addition, some scales examined ratings on traits generally considered socially desirable for both sexes, such as "happy."

\section{METHOD}

\section{Subjects}

Twenty-one black women and 21 white women, all students at a large midwestern university, served as voluntary subjects. The participants lived in the same residence hall as one of the authors and could not be considered as a random sample of black and white women college students. The residence hall is typical of the dormitories at the university with respect to demographic characteristics.

\section{Procedure}

Each subject rated black and white men on all 60 items of the Bem instrument. The order of rating men of the two races was approximately counterbalanced by randomly assigning half of the women of each race to rate black or white men first. Ten black and 11 white women rated black men before rating white men, and 11 black women and 10 white women rated white men before they rated black men. The experimental sessions were conducted in a room in the residence hall. Each subject was given a copy of the Bem scale and told to rate black males (if assigned to rate black males first) or to rate white males (if assigned to that condition). After they had completed the ratings, the sheets were collected and another copy of the scale was distributed. This time the subjects were told to rate the other group of men.

\section{Materials}

The Bem Androgyny Scale (Bem, 1974) was selected as the test instrument because the scale provides for the independent assessment of traits usually attributed to males, to females, and to both sexes. Comparisons may be made between ratings on the masculine and feminine scales to assess the relative attributions on these traits. The relative attributions constitute an index of androgyny as defined by Bem.

The Bem scale contains 20 items that tap traits considered socially desirable for females (the feminine scale), 20 items associated with traits considered socially desirable for males (the masculine scale), and 20 items associated with traits considered socially desirable for either sex (the social desirability scale). Some examples of these traits are "yielding, affectionate, gentle, compassionate" (feminine scale), "self-reliant, defends own beliefs, independent, ambitious" (masculine scale), and "happy, helpful, reliable, truthful" (social desirability scale). Each item is rated on a continuum from 1 (never or almost never true) to 7 (always or almost always true).

\section{RESULTS}

\section{Masculinity}

The predictions generated from the opposite culture perspective were that black women would characterize black men as less masculine than white men, and that white women would rate men of both groups in the same way but that the differences would not be as marked as those shown by black women. The predictions of the cultural halo model were that black women would attribute more masculine traits to black men than to white men, while the opposite would be true for white women.

To assess the support for these predictions, the ratings assigned by black and white women on the 20 masculine items were calculated for black and for white males. Then, in accordance with the calculation of masculinity as defined by Bem, the mean ratings, summed over the 20 masculine items, were computed. The possible range of this metric was from 1 (low masculinity) to 7 (high masculinity).

The mean masculinity ratings attributed by each group of women to black and to white males are depicted in the upper left panel of Figure 1. These means showed trends that were consistent with the predictions of the cultural halo position. Black women attributed more masculine traits to black men than they did to white men, whereas white women attributed slightly more masculine traits to white men than to black men. These mean ratings were subjected to an analysis of variance that treated the two groups of subjects as a between-subjects variable and the two racial groups of men as a within-subjects variable. The difference for the main effect of the black and white women was not statistically significant $(F<1)$, indicating that, overall, the black and white women did not differ in their ratings. Both the main effect for the differential ratings of black and white men $[F(1,40)=14.63, p<.01]$ and the interaction between the two variables $[F(1,40)=26.18, p<.01]$, however, 

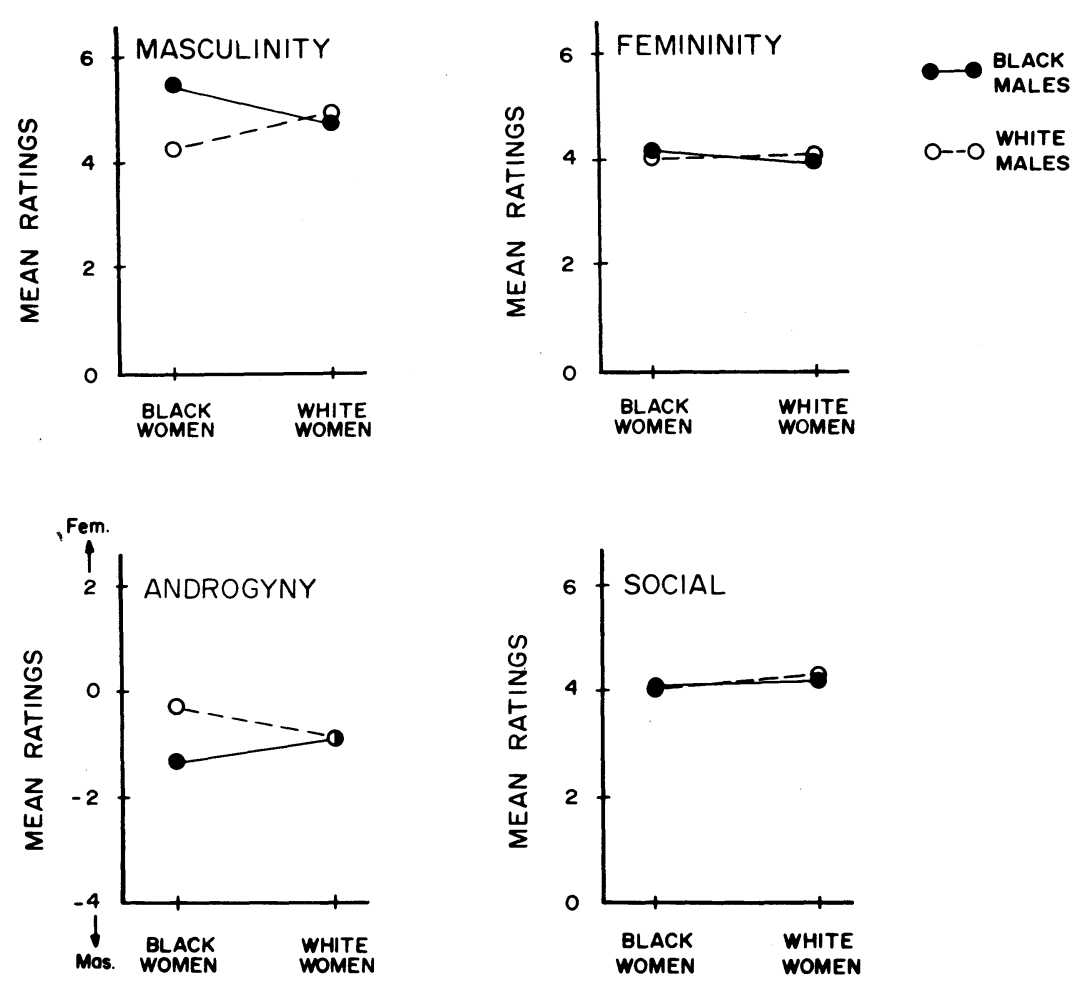

Figure 1. Mean ratings of black and white men by black and white women on the four measures.

were significant. In general, black men were rated as more masculine (mean $=5.13$ ) than white men (mean $=4.61$ ), but this main effect occurred because of the overwhelming effects of the fairly extreme ratings of black men by black women, as depicted in Figure 1.

The individual means contributing to the interaction were compared using Tukey tests. These tests showed that the difference between the ratings assigned to black and white men by black women was significant beyond the .01 level, but that the slight tendency for white women to rate white men as more masculine than black men was not significant. Thus, the most reasonable interpretation of the interaction was that black women rated black men as more masculine than white men, while white women attributed a level of masculinity to men of both races that was intermediate between the ratings assigned by the black women.

\section{Femininity}

The two theoretical positions also yielded different predictions about ratings of femininity. The opposite culture view held that black women would attribute more feminine traits to black men than to white men; the cultural halo position predicted the opposite. The support for these predictions was examined by conducting an analysis of variance on the mean ratings of the 20 feminine traits. These ratings also had a potential range of from 1 (low femininity) to 7 (high femininity). The mean ratings on the feminine traits were then analyzed using the technique described for the analysis of the masculinity ratings. The mean ratings on feminine traits assigned by black women to black and to white men were 4.19 and 4.04 , respectively, and the mean ratings assigned by white women to black and to white men were 3.92 and 4.09 . Obviously, both black and white women attributed some feminine characteristics to men of both races. No difference was significant for femininity, as shown in the upper right panel of Figure 1, thus refuting both models. Women of both races attributed approximately the same intermediate level of feminine traits to men of both races, indicating that black and white men were rated as similar to each other with respect to such traits as cheerfulness, gentleness, yieldingness, and so on.

\section{Social Desirability}

The 20-item social desirability scale was analyzed in the same manner. The mean ratings of social desirability attributed by black women to black and to white men were 4.07 and 4.05 , respectively; the mean ratings assigned by white women to black and to white men were 4.15 and 4.25 . Even though there appeared to be a tendency for white women to attribute more socially desirable traits to men of both races, these differences were not significant (see lower right panel of Figure 1), nor were any of the other analyses. Therefore, the results indicated that women of both 
races assigned approximately the same levels of traits such as happiness, reliability, and truthfulness to black and to white men.

\section{Androgyny}

Bem (1974) related androgyny to the difference between a person's score on the femininity and masculinity subscales. Thus, androgyny reflects a balance between feminine and masculine traits, with negative scores representing more masculine than feminine characteristics and positive scores indicating more feminine than masculine characteristics. We calculated the index of androgyny by subtracting the mean of the ratings for masculinity from the mean of the ratings for femininity for each subject's attribution to one group of men. This measure was used, rather than the $t$ ratio originally recommended by Bem, because the two indices are virtually identical (Bem reported the correlation between the two measures to be .98). Black men were rated as less androgynous than white men $[\mathrm{F}(1,40)=15.33, \mathrm{p}<.01]$, reflecting the heavier weight of the masculine traits that were assigned to black men. Further, the interaction was reliable $[F(1,40)=16.80, p<.01]$. As shown in the lower left panel of Figure 1, black women rated black men as less androgynous (possessing a greater preponderance of masculine than feminine characteristics) than white men, but white women rated men of both races as about the same in androgyny (also weighted more heavily toward masculinity). The stimulus group receiving the most androgynous ratings were white men rated by black women.

\section{DISCUSSION}

In general, the results of this exploratory study suggested the differential attribution of masculine traits to white and to black men by black women but not by white women. Black men were characterized by this group of black women as more masculine than white men. However, because black men were rated as possessing feminine traits similar to those possessed by white males, black males received scores signaling less androgyny than white males. Specifically, the differential in androgyny indicated that these black women assigned to black men a greater preponderance of masculine than feminine traits, whereas they attributed more nearly equal proportions of masculine and feminine traits to white men. White women participating in this study rated men of both races as similar, but more masculine than feminine.

The attributions found in this exploratory work supported the hypothesis that black college women would assign a more extreme masculine role to black men than to white men. Thus, these results disconfirmed the opposite culture position's expectation that black women would attribute more feminine and fewer masculine traits to black men than to white men.

The data were consistent with the cultural halo hypothesis: Ethnic pride would result in greater emphasis being placed on distinctive traits usually considered socially desirable for the sex. This position implied that the traits considered socially desirable for men would be accentuated by minority group members, but that the traits usually considered less socially desirable (for men, in this case, the feminine traits) would not be accentuated. Not only were black men judged to be more masculine than white men by these black women, but the black women attributed about the same level of feminine characteristics to black men as to white men.

If the trends observed herein are replicated, the findings would have important implications for the understanding of the development of sex-role expectations, of ethnic ideology, and the interaction between the two. At this stage, it seems plausible to conceptualize the development of sex roles as a process of modification of the cognitive aspects of appropriate sex-role behavior by the concepts and conditions imposed by other roles that contribute to self-identity, including ethnic characteristics. This approach is consonant with the view that members of a minority group may conceptualize appropriate roles for the sexes as a pattern that is similar to but more extreme in the most salient aspects for the sex than the conceptualizations majority persons have for appropriate sex roles.

\section{REFERENCES}

BEM, S. L. The measurement of psychological androgyny. Journal of Consulting and Clinical Psychology, 1974, 42, 155-162.

Broverman, I. K., Vogel, S. R., Broverman, D. M., Clarkson, F. E., \& Rosenkrantz, P. S. Sex-role stereotypes: A current appraisal. Journal of Social Issues, 1972, 28, 59-78.

Epstein, C. F. Black and female: The double whammy. Psychology Today, 1973, 7, 57-61.

GuMP, J. P. Comparative analysis of black women's and white women's sex-role attitudes. Journal of Consulting and Clinical Psychology, 1975, 43, 858-863.

LA RuE, L. The black movement and woman's liberation. In S. Cox (Ed.), Female psychology: The emerging self. Chicago: Science Research Associates, 1976.

LeRner, G. (Ed.). Black women in white America. New York: First Vintage Books, 1973.

McKee, J. P., \& Sherriffs, A. C. Men's and women's beliefs, ideals, and self concepts. American Journal of Sociology, 1959, 64, 356-363.

Moynihan, D. P. The Negro family. Washington, D.C: Office of Policy Planning and Research, U.S. Department of Labor, 1965.

Murray, S. R., \& Mednick, M. T. S. Perceiving the causes of success and failure in achievement: Sex, race and motivational comparisons. Journal of Consulting and Clinical Psychology, 1975, 43, 881-885.

O'Leary, V. E., \& Depner, C. E. College males' ideal female: Changes in sex-role stereotypes. Journal of Social Psychology, 1975, 1, 139-140.

Peterson, M. J. The asymmetry of sex-role perceptions. Sex roles: A Journal of Research, 1975, 1, 267-282.

Pettigrew, L. A profile of the Negro American. Princeton: Van Nostrand, 1964.

Poussaint, A. F. A Negro psychiatrist explains the Negro psyche. In C. H. Steele \& N. R. Yetman (Eds.), Majority and minority: The dynamics of racial and ethnic relations. Boston: Allyn \& Bacon, 1971.

Rosenkrantz, P., Vogel, S., Bee, H., Broverman, I., \& Broverman, D. M. Sex-role stereotypes and self-concepts in college students. Journal of Consulting and Clinical Psychology, 1968, 32, 287-295.

Weston, P. J., \& Mednick, M. T. Race, social class, and the motive to avoid success in women. Journal of CrossCultural Psychology, 1970, 1, 284-291.

(Received for publication January 28, 1978.) 